\title{
C) GitsentórICA
}

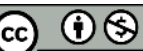

\section{O declínio do homem provedor chefe de família: entre privilégios e ressentimentos}

The decline of the male breadwinner: between privileges and resentments

\section{Caíque Diogo de Oliveira"}

Resumo: As mudanças no âmbito dos domicílios, na sociedade brasileira, pós-década de 1990, resultaram em mudanças na condição e no comportamento masculino. Assim, buscase investigar como o declínio da hegemonia do homem como chefe de família se articula a construção social da masculinidade em seu período. Parte-se de uma pesquisa de caráter exploratória que recorre a fontes documentais e bibliográficas. Os dados apontam que em I995 cerca de 23\% dos domicílios eram chefiados por mulheres, em 2019 esse percentual é de $48 \%$. Esse movimento no chefiamento do lar coincide com um contexto no qual os homens tem cada vez se ressentido com as conquistas femininas/feministas. Sem perceber os frutos do privilégio da condição de gênero, bem como das mudanças no capitalismo em sua dimensão neoliberal, os homens têm assumido uma posição ressentida buscam no passado um lugar onde encontram segurança.

Palavras-chave: Gênero; Masculinidades; Neoliberalismo; Chefiamento familiar

Abstract: The changes in the scope of families, in Brazilian society, after the I990s, resulted in changes in male condition and behavior. Thus, we seek to investigate how the decline in the hegemony of men as the breadwinner articulates the social construction of masculinity in their period. It is based on an exploratory research that uses documentary and bibliographic sources. The data show that in 1995 about $23 \%$ of households were headed by women, in 2019 this percentage is $48 \%$. This movement in the head of the home coincides with a context in which men have increasingly resented the feminist/feminist conquests. Without recognize the fruits of the privilege of the gender condition, as well as of the changes in capitalism in its neoliberal dimension, men have taken a resentful position looking in the past for a place where they find security.

Keywords: Gender; Masculinities; Neoliberalism; Breadwinner

"Doutorando do Programa de Pós-Graduação em Educação da Universidade Federal de São Carlos campus Sorocaba. Bolsista CAPES. E-mail: caique.diogo@outlook.com.br 


\section{C) GitistóñóRICA}

As conquistas femininas em fins do século XX e início do século XXI sinalizam com mudanças na sociedade brasileira. As mulheres já vivem em média 7 anos a mais do que os homens, são maioria do eleitorado brasileiro, ultrapassaram eles em todos os níveis educacionais, aumentaram a sua participação no mercado formal de trabalho, reduzindo as diferenças salariais, e são maioria dos/das beneficiários/beneficiárias da previdência e dos programas de assistência social.

Essas mudanças produziram impactos também no âmbito familiar. No Brasil, as famílias chefiadas por mulheres passaram a crescer cada vez mais. Estudos têm acompanhado esse processo de crescimento das famílias chefiadas por mulheres relatando os impactos que essa mudança de natureza demográfica e social implicam para a vida das mulheres (PERUCCHI; BEIRÃO, 2007; D'AVILA, 2008; MACEDO, 2008; OLIVEIRA, 20I4; OLIVEIRA, 20I8). Considerando o caráter relacional do gênero, no qual mudanças no comportamento das mulheres promovem mudanças no comportamento dos homens (SCOTT, I995), este artigo pretende problematizar as implicações sobre os homens nesse novo cenário.

O chefiamento masculino deriva de uma relação dos homens com o trabalho remunerado, que, por sua vez, é historicamente um espaço ocupado pelos homens. Esse tipo de trabalho continua a ser um dos construtores da base de respeitabilidade masculina, na medida que permite ao homem obter reconhecimento, segurança e os ganhos para prover o lar. A figura do provedor chefe de família foi forjada nos valores familiares heteronormativos e no poderio econômico fruto dessa inserção na esfera pública. O trabalho que explora também é um refúgio, onde os homens não precisam realizar as tarefas do trabalho doméstico, de cuidado dos/das outros/outras, de demonstrar afeto (HOOKS, 2004). Na racionalidade fria do trabalho os homens afirmam a supressão de sentimentos. Assim, seja como o empreendedor ou como o assalariado, os homens construíram sua respeitabilidade enquanto homens a partir da dimensão produtiva do trabalho na esfera pública (KIMMEL, 1998).

A busca dos homens por se diferenciarem daquilo que julgam ser feminino é histórica (BAUBÉROT, 20I3), se estendendo até às gerações atuais (KIMMEL, 20I8a). Ser chefe de família propicia, para homens e mulheres, um campo de disputas de poder e significação de si e do outro. Investigar as mudanças no chefiamento das famílias na atualidade possibilita compreender mais um histórico lugar de construção da masculinidade, e desta forma, refletir sobre continuidades e permanências que envolvem a construção social e cultural de homens e mulheres. Prosseguindo na reflexão anterior, ao olhar para esse cenário de 


\section{C) GitistóñICA}

mudanças nas relações de gênero (OLIVEIRA, 2020), busca-se investigar, a partir do contexto brasileiro, o declínio da hegemonia do homem como provedor central da família, situando essas mudanças frente as expressões masculinas de ressentimento no contexto neoliberal pós-crise financeira de 2008.

O estudo procura combinar dados demográficos de ordem documental com elementos conceituais na busca de estabelecer "jogos de escala", nos quais confronta-se a ordem social em relação às questões individuais. Para investigar as expressões de masculinidade no chefiamento das famílias em relação a dinâmica macrossocial, o estudo fez uso de fontes de dados quantitativos de bancos estatísticos como o Instituto Brasileiro de Geografia e Estatística - IBGE - e o Instituto de Pesquisa Econômica Aplicada - IPEA -, bem como em relatórios de investigação demográfica sobre as mudanças familiares.

Ao direcionar essa problematização sobre os homens no âmbito da família, pretendese manter a tradição de estudos críticos sobre masculinidades (OLIVEIRA, 1998). Essa preocupação significa colocar a dominação masculina em exame, tomando como ponto de partida os privilégios de gênero, não como simples retórica de militância ou como sinônimo de direitos historicamente conquistados, mas, como ferramenta analítica da condição masculina.

Com o declínio do homem como provedor chefe de família, os homens sentem que seus "direitos" estão sendo lesados, e assim alguns deles têm expressado uma das manifestações masculinas contemporâneas diante desse cenário: o ressentimento expresso no desejo de voltar ao passado.

\section{Olhares sobre o chefiamento do lar}

Se diversas são as pesquisas que tem olhado para a mulher no transcorrer dessa mudança no chefiamento do lar (PERUCCHI; BEIRÃO, 2007; D’AVILA, 2008; MACEDO, 2008; OLIVEIRA, 20I4; OLIVEIRA, 20I8), tem-se discutido pouco sobre como os homens tem lidado com esse processo. Investigar estes impactos na construção social do gênero a partir do processo de chefiamento dos domicílios envolve um caminho metodológico de exposição dos dados que precisa integrar as mudanças no mundo do trabalho com as mudanças no âmbito das famílias. Conforme aponta Macedo (2008, p. 394)

Significa dizer que é preciso entender como a precarização das condições de vida da população - através do entrelace de questões como a reestruturação produtiva, as redefinições nas regras do mercado de trabalho e no papel do Estado - articulam-se a fatores demográficos - como a ocorrência de novos fluxos migratórios, a redução da fecundidade, o 


\section{C) Hitsistórica}

aumento do número de divórcios, a ampliação da expectativa de vida (associada à manutenção das taxas de sobremortalidade masculina) e o crescimento relativo das uniões consensuais e das chamadas "produções independentes" -, o que resulta em novos arranjos do tipo monoparental.

Posto que este artigo busca se aproximar dessa relação dos homens com as mudanças no chefiamento feminino, é possível defini-lo como exploratório, pois, tais estudos permitem ao investigador aumentar sua experiência em torno de determinado problema, estabelecendo variáveis, de modo que futuramente possa formular problemas mais precisos (GIL, 2008). Além disso, ao buscar detalhes, se aproximando da pesquisa descritiva, a natureza da pesquisa exploratória articula-se aos objetivos deste estudo, a medida que este assume uma busca por investigar mudanças no chefiamento familiar e suas implicações sobre os homens via apontamentos de ordem demográfica.

A pesquisa documental é parte da estratégia de colocar em diálogo um olhar sobre a relação entre a macroestrutura e a microestrutura. Considerando que a ação dos indivíduos resulta da relação que se estabelece entre indivíduo e sociedade, a compreensão das experiências individuais passa pela compreensão das dimensões estruturais da sociedade. A perspectiva metodológica que norteia esse estudo se inspira no debate realizado sobre os “jogos de escala” (REVEL, 1998).

Essa abordagem constitui-se em um recurso fecundo que possibilita a construção de sentidos sobre objetos situados entre macrodados e microdados, não concebendo-os como extremos isolados, mas, como pertencentes a um mesmo contínuo (BRANDÃO, 2008). Os jogos de escala buscam superar a dicotomia entre expressões em nível macrossocial e microssocial, busca apontar como a dimensão "micro" dos comportamentos são articulados as dinâmicas observáveis que ocorrem na dimensão "macro" (REVEL, I998).

Em um primeiro momento, para investigar essas mudanças em processo, busca-se em fontes documentais dados quantitativos para apontamentos dessas mudanças em curso. Esses dados quantitativos foram obtidos em bancos de dados como o IBGE e o IPEA e relatórios de natureza demográfica. Além disso, recorre-se a fontes secundárias de ordem conceitual para caracterizar os aspectos de gênero e masculinidades.

O método de pesquisa sobre o chefiamento domiciliar nem sempre foi o mesmo. A investigação aparece nos sensos desde a década de 1940, contudo, o avanço das pesquisas, acompanhadas da mudança no método investigativo para definir o que é o chefiamento domiciliar é embalado pela consolidação de importantes associações científicas nacionais, trazendo novas definições para a identificação do fenômeno. Conforme aponta Márcia Macedo (2008) o chefiamento feminino é histórico no Brasil, especialmente entre os setores 


\section{C) HitistórRICA}

populares, e com as mudanças da década de 1980 em diante, o fenômeno vem chegando às camadas médias e ganhando maior visibilidade social com a desconstrução do olhar sobre a constituição familiar.

De forma geral, a família censitária é composta pelas pessoas que residem em domicílios particulares e mantém entre si parentesco, conjugalidade ou convivência doméstica. Situar essas famílias em um domicílio passa por um propósito técnicooperacional (CAVENAGHI, ALVES, 20I8). Ainda que a preocupação desse estudo seja combinar dados sobre elementos demográficos à repercussões no âmbito dos indivíduos, o método quantitativo também possui limites ao trazer dados sobre um "sujeito médio", dificultando uma investigação mais ampliada sobre a pluralidade de modelos familiares e suas práticas culturais de gênero (MACEDO, 2008). Reconhecer isso é importante para delimitar as contribuições possíveis que esse estudo pode propiciar.

\section{Apontamentos sobre gênero e masculinidades}

Ao realizar estudos sobre masculinidades e a construção cultural dos homens é fundamental atentar para a origem da temática no campo de estudos de gênero e, concomitantemente, ao debate pró-feminismo.

$\mathrm{O}$ conceito de gênero tem sua origem na segunda metade do século XX e nasce como instrumento da crítica feminista no campo acadêmico. A introdução do conceito de gênero nas pesquisas produziu uma transformação nos paradigmas disciplinares/epistemológicos. Segundo Scott (1995, p.73) “As pesquisadoras feministas assinalaram desde o início que o estudo das mulheres não acrescentaria somente novos temas, mas que iria impor um reexame crítico das premissas e dos critérios do trabalho científico existente". Essa contestação vem sendo cumprida colocando até a obra de clássicos como objeto de investigação de gênero (CHABAUD-RICHTER, 20I4).

Com a maior inserção feminina nas universidades, as demandas do debate feminista chegaram ao campo da História, de modo que esforços foram realizados para o reconhecimento do papel das mulheres na história (SCOTT, 1995). Cada vez mais pesquisas foram realizadas buscando explorar a História das mulheres e a importância que tiveram nos rumos dos acontecimentos (PERROT, 2007). Na esteira desse movimento, há também uma discussão, mais recente, sobre a História dos homens, revelando expressões da masculinidade em contextos históricos específicos (DEL PRIORE; AMANTINO, 20I3; CORBIN, COURTINE, VIGARELLO, 20I3). 


\section{C) Hitsistórica}

Em diálogo com as mudanças no âmbito da história, Raewyn Connell (2016) entende que as heranças coloniais, pós-coloniais e neocoloniais são importantes para a interpretação do gênero. A autora afirma que há uma ligação entre a constituição das masculinidades e as transformações sociais, ou seja,

O gênero não está separado e guardado em um armário próprio. Está, sim, embrenhado nas mutantes estruturas de poder e reviravoltas econômicas, no movimento das populações e na criação das cidades, na luta contra o apartheid e nos lapsos do neoliberalismo, nos efeitos institucionais das minas, prisões, exércitos e sistemas educacionais (CONNELL, 2016, p. 33).

Além de um substituto para a categoria "mulheres"I, "O termo "gênero" [..] é também utilizado para sugerir que qualquer informação sobre as mulheres é necessariamente informação sobre os homens, que um implica o estudo do outro" (SCOTT, 1995, p.75). Estudos de gênero têm alertado a necessidade de superar a dicotomia entre masculinidade e feminilidade para interpretar o fenômeno do gênero. Críticas realizadas a essa essencialização e reducionismo do debate trazem contribuições para o desdobramento da investigação relacional, na qual a condição dos homens e das mulheres se articulam (ROSALDO, 1994). As demandas de reflexão trazidas pelo movimento LGBT na segunda metade do século XX e início do século XXI ampliam os debates no campo de estudos de

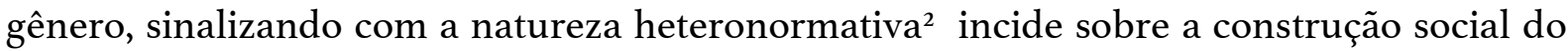
gênero e das sexualidades (BUTLER, 2003).

Considerar o papel da heteronormatividade na construção social do gênero possibilita pensar masculinidades e feminilidades como resultante de um set institucionalizado de práticas que os indivíduos assimilam em maior ou menor grau (BRANON; DAVID, I976; KIMMEL, 20I8a). Além da dimensão prática, há também sentidos atrelados ao gênero que envolvem concepções rígidas ou fluídas sobre o que é o masculino e o feminino, ou sobre estar entre ambos. Segundo Bethany Coston e Michael Kimmel (2OI2) o gênero opera tanto no âmbito da interação, considerando que os indivíduos fazem gênero, quanto no âmbito da identidade, entendendo que o indivíduo tem um gênero.

\footnotetext{
I Segundo Piscitelli (2002, p.I2)A categoria mulher “[...] tem raízes na ideia do feminismo radical segundo a qual, para além de questões de classe e raça, as mulheres”. A categoria mulheres possibilitou a reflexão sobre as desigualdades em relação aos homens, sendo posteriormente incorporada a discussão promovida pelo feminismo negro e o debate sobre interseccionalidades.

${ }^{2}$ Procurando definir a heteronormatividade Petry e Meyer afirmam que "A heteronormatividade visa regular e normatizazar modos de ser e de viver os desejos corporais e a sexualidade. De acordo com o que está socialmente estabelecido para as pessoas, numa perspectiva biologicista e determinista, há duas - e apenas duas - possibilidades de locação das pessoas quanto a anatomia sexual, ou seja, feminino/fêmea ou masculini/macho" (PETRY; MEYER, 20II)
} 


\section{C) Hitsistórica}

Mais especificamente em relação aos estudos sobre masculinidades, pode-se dizer que eles acompanham o desenvolvimento do conceito de gênero durante a década de 1980 . Assim, como a categoria gênero desconstruiu a categoria mulher, a investigação das masculinidades difundiu a desconstrução da categoria homem como fechada em um único papel social. Destaque para os homens engajados no feminismo e as feministas negras que abriram caminho para a formulação teórica a medida que colocaram em questão a pressuposição racializada do patriarcado e os papéis sociais. Pois, homens brancos e homens negros reproduziam comportamentos machistas em diferentes lugares e de diferentes formas. Os debates acerca do movimento gay também foi importante para auxiliar na compreensão e proposição de uma diferenciação entre os homens.

Da década de 1990 em diante, pesquisas sobre a construção social das masculinidades passaram a ser produzidas nos cinco continentes do globo (CONNELL; PEARSE, 2016). No interior desse campo identifica-se três operadores analíticos utilizados nos estudos sobre masculinidades: o princípio da virilidade3(CORBIN, COURTINE, VIGARELLO, 20I3; BOURDIEU, 20I8); as masculinidades hegemônicas e subalternas ${ }^{4}$ (CONNELL; MESSERCHMIDT, 2013; CONNELL; PEARSE, 20I6); a assimilação dos códigos masculinos5 (BRANON; DAVID, 1976; POLLACK, I999; KIMMEL, 20I8a).

Os homens realizam estratégias de afirmação no espaço público, tomando ações tanto para afirmar sua masculinidade na presença de mulheres como também na presença

\footnotetext{
3 Investigar a masculinidade a partir do princípio da virilidade é algo associado a análises históricas que buscam no homem um valor comum e distintivo. A virilidade é o que há de comum entre um guerreiro, um trabalhador e um esportista, isso pode ser visto em diferentes culturas. Segundo Bourdieu "A virilidade, em seu aspecto ético mesmo, isto é, enquanto qualidade do vir, virtus, questão de honra (nif), princípio da conservação do aumento da honra, mantém-se indissociável, pelo menos tacitamente, da virilidade física, através, sobretudo, das provas de potência sexual" (BOURDIEU, 20I8, p.25). Portanto, o princípio da virilidade não deve ser encarado como uma perspectiva do passado, mas seu uso precisa ser historicizado com todo cuidado para que tanto concepções anacrônicas não sejam empregadas no olhar sobre o masculino, como novos problemas e questões que atravessam a masculinidade emerjam.

${ }_{4}$ Segundo Connell e Messerchmidt (2013) as investigações sobre masculinidades hegemônicas e subalternas propõe estabelecer as tipologias a partir de uma hierarquização. A masculinidade hegemônica não se assumiu normal num sentido estatístico; nela, uma minoria dos homens talvez a adote, contudo, ela assume um sentido normativo. A tipologia hegemônica expressa a forma mais honrada de ser um homem, ela exige que todos os outros homens se posicionem em relação a ela e legitima ideologicamente a subordinação das minorias políticas - mulheres, homens negros e homens gays, bissexuais, assexuais e transsexuais. Essa disputa, baseada em uma hierarquia, em busca da hegemonia possui influência direta do pensamento de Antonio Gramsci. Vale ressaltar que a masculinidade hegemônica não é necessariamente buscada por todos os homens. A identificação dos grupos e do posicionamento dos mesmos na hierarquia não é estático. A medida que elas são caracterizações criadas a partir das relações materiais e históricas, elas assumem uma função representacional. 5 Trata-se de um set institucional composto por diversas ações que devem ser assimiladas para que os rapazes sejam considerados "homens de verdade". Considerar a coleção de regras, preceitos e preconceitos aos quais os homens devem seguir para obter reconhecimento de gênero, envolve diferentes tipos de produções. Isso envolve desde códigos prescritos entre si, assumindo um sentido normativo a respeito do que eles dever ser/fazer, até exames críticos sobre o que os homens devem fazer para serem percebidos enquanto tais.
} 


\section{C) GitistóñICA}

de outros homens (KIMMEL, I998). Isso fica evidente na imersão em grupos masculinos conduzida pela jornalista Norah Vincent (2006) na obra Feito Homem. No convívio com grupos masculinos, a autora percebe que há necessidade de se comportar de forma à atender alguns padrões específicos, no qual a insegurança em relação ao outro é constante, e os rapazes precisam demonstrar que são merecedores de pertencimento no grupo. Segundo a autora, ainda que haja uma relação de camaradagem entre os rapazes, ela é atravessada constantemente por uma compulsória ausência de demonstração de sentimentos e afetos.

Essa supressão de sentimentos e afetos, afirmações da masculinidade na esfera pública e a valorização de um status de "homem de verdade" são indicativos de como a masculinidade é baseada em um sentimento, quase estóico, de estar/manter-se no controle. De maneira que

[...] masculinidade é baseada em impermeáveis defesas e o sentimento de estar no controle, então a violência pode ser restaurativa, retornando à situação do momento antes que o senso de vulnerabilidade e dependência foi sentido e o senso de masculinidade foi comprometido" ${ }^{6}$ (KIMMEL, 20I7, p. 177).

Esse imperativo que informa aos homens que eles devem estar no controle, enfrenta grandes desafios quando se depara com o contexto social neoliberal e sua macroestrutura na qual há ausência de empregos, concentração de renda e uma instabilidade constante na vida conjugal. Esse aspecto será discutido a seguir, mas, antes, breves apontamentos sobre os privilégios masculinos.

\section{Privilégio e a invisibilização dos conflitos de gênero}

A reflexão sobre os privilégios ocupa um espaço relevante em alguns discursos de militância (MCINTOSH, 20IO). Entretanto, propõe-se tomá-lo como um conceito analítico para a compreensão das vantagens obtidas pelos homens. Há uma literatura que fomenta esse uso teórico da palavra para investigações sociais (KIMMEL; FERBER, 20IO; KHAN, 20II). O conceito pode ser aplicado nos diversos marcadores da diferença, isto é, há privilegiados na condição de gênero, raça, classe e/ou religião. Portanto, falar sobre homens no chefiamento do lar é falar também sobre privilégios.

\footnotetext{
${ }^{6}$ Tradução livre do próprio autor a partir de: [...] masculinity is based on impermeable defenses and the feeling of being in control, then violence may be restorative, returning the situation to the moment before that sense of vulnerability and dependency was felt and one's sense of masculinity was so compromised (KIMMEL, 20I7, p. I77)
} 


\section{C) Hitistór RICA}

O privilégio não é sinônimo de direitos sociais, haja vista que se corre o risco de apagar/destituir os direitos básicos conquistados se tomá-los como privilégios. Mais do que um marcador social que credita direitos, o privilégio pode ser investigado como um mecanismo de invisibilização. Para além de distribuir direitos de forma desigual, o privilégio tende a invisibilizar os marcadores sociais fazendo com que os indivíduos não percebam sua condição social a partir desses marcadores. Discutir tais isenções têm como objetivo tornar visível para aqueles/aquelas cuja condição de gênero, sexualidade, raça, classe, detém vantagens socialmente adquiridas sem perceber.

Para os homens, o privilégio muitas vezes é algo que surge invisibilizado nas relações sociais, quer dizer, é possível observar a presença de homens em diversos lugares, grupos e instituições. Eles compõem maioria em diversas profissões nos setores de transportes, militar e mineração (MARQUES, 20II). Entretanto, por tais mecanismos, eles não se percebem como predominantes e reguladores desses espaços.

A estratégia tradicionalmente utilizada para confrontar os privilégios envolve um aprofundamento do olhar sobre os processos de marginalização e a tentativa de sensibilizar aqueles que estão no centro, sobre as possibilidades de mudança. Essa estratégia tende a colocar aqueles que estão no centro, usufruindo de benefícios em uma posição defensiva e de negação da responsabilidade na construção de direitos iguais para todos e todas (KIMMEL; FERBER, 20IO).

Confrontar os privilégios nem sempre é um exercício confortável, porém, necessário. Ao discutir sobre os benefícios adquiridos com somente pelos marcadores da diferença prestigiados, os indivíduos se sentem em risco, a tal ponto que, medo, insegurança e desconforto acompanham o debate. Esse risco deriva de uma sociedade individualista que busca individualizar a culpa, ignorando o papel coletivo das construções simbólicas que motivam o comportamento (JOHNSON, 20IO). O reconhecimento do privilégio deve ser feito junto com o reconhecimento da dimensão coletiva de produção dos mesmos, isto é,

Indivíduos e sistemas estão conectados uns aos outros por meio de um relacionamento dinâmico. Se usarmos esse relacionamento como um modelo para pensar sobre o mundo e sobre nós mesmos, será mais fácil trazer à tona problemas como racismo, sexismo e heterossexismo e falar sobre eles? (JOHNSON, 20IO, p. 82)

\footnotetext{
7 Tradução livre do próprio autor a partir de: "Individuals and systems are connected to each other through a dynamic relationship. If we use this relationship as a model for thinking about the world and ourselves, its easier to bring problems like racism, sexism, and heterosexism out into the open and talk about them".
} 


\section{C) GitistóñICA}

As abordagens da interseccionalidade e dos marcadores da diferença contribuem para a reflexão sobre tais mecanismos, e sua distribuição desigual. Ao falar sobre privilégio masculino, a representação mais comum é a do homem branco, heterossexual, que possui acesso as melhores posições no mercado de trabalho e consome os melhores bens disponíveis. Nesse sentido, a abordagem interseccional evidencia que nem todos os homens usufruem de vantagens da mesma maneira, que o privilégio de gênero pode ser combinado com a opressão do racismo e/ou a homofobia (KAUFMAN; KIMMEL; COSTON KIMMEL; HILL COLLINS, 20I0).

Ainda que o mérito como regulador das relações sociais possa ser proposto como um meio para promover a justiça, pela chamada meritocracia, ao desconsiderar as assimetrias sociais, pode ocultar os direitos adquiridos por meio de marcadores sociais. Ao desconsiderar essas assimetrias sociais, a meritocracia funciona como uma justificativa que legitima desigualdades enquanto interpreta o indivíduo como não-pertencente a nenhum marcador da diferença, isto é, sem gênero, raça, classe, religião, escolaridade. O individualismo também emerge junto a meritocracia, e com ele, a invisibilização promovida por tais mecanismos. Assim sendo, discutir privilégios envolve também discutir o individualismo e a meritocracia.

No âmbito do trabalho, os homens colhem diversos frutos de seus privilégios, a renda do trabalho é um deles. Ao verificar os rendimentos do trabalho no ano de I995, percebe-se que para cada $\mathrm{R}$ \$I ganho por uma mulher, um homem ganhava $\mathrm{R} \$ \mathrm{I}, 89$, isto é, os frutos do privilégio rendiam aos homens 0,89 centavos a mais por real ganho entre as mulheres. Já em 20I8, pouco mais de duas décadas depois, esse valor diminuiu; para cada $\mathrm{R}$ I obtido pelas mulheres via trabalho, os homens recebem em média $\mathrm{R} \$ \mathrm{I}, 27$, ou seja, o privilégio de gênero passou a "render" $\mathrm{R} \$ 0,27$ centavos a mais.

Enquanto as mulheres buscam conquistar esse espaço, os homens possuem representação há séculos. Segundo Helena Hirata (2010) a divisão sexual do trabalho faz com que os homens ocupem o trabalho na esfera pública, especialmente setores militares, políticos e industriais, ao passo que as mulheres realizam o trabalho concernente a esfera privada, como as tarefas domésticas, a saúde e a educação, isto é, a esfera do cuidado. Além da lógica de divisão, trabalho masculino e feminino também respondem a uma lógica de hierarquização, na qual os homens também obtêm vantagens. Segundo essa lógica, o trabalho dos homens é mais valorizado que o trabalho das mulheres. Todavia, essa divisão e hierarquização são transitórias e variam a depender do período histórico e sociedade observados. 


\section{C) GitistóróRICA}

Embora os privilégios de gênero sejam relevantes; no Brasil, o recorte racial também deve ser realizado para uma interpretação mais aprofundada da realidade dos/das brasileiros/brasileiras. Esse mesmo ganho médio, possui elementos intragênero. O hiato racial entre homem branco e homem negro no ano de 1995 pode ser expresso no trabalho à medida que para cada R \$I ganho pelo homem negro, o homem branco recebia em média $\mathrm{R}$ \$2,15. Contudo, essa disparidade diminuiu com o passar dos anos, em 20I8, essa diferença que era de $\mathrm{R} \$ \mathrm{I}, \mathrm{I} 5$ entre os dois, passou para $\mathrm{R} \$ \mathrm{o}, 80$; isto é, para cada $\mathrm{R}$ I ganho pelo homem pardo ou preto, o homem branco recebe $\mathrm{R} \$ \mathrm{I}, 80$.

Em síntese, o aumento na renda média das mulheres e dos homens negros significa o acirramento de conflitos na busca por um espaço no mercado de trabalho, especialmente em ocupações com direitos provenientes das conquistas da classe trabalhadora.

\section{O declínio do provedor chefe de família}

A vida de homens e mulheres, no Brasil, passou por transformações da década de 1990 até o fim da década de 20I0, período no qual ocorre tanto a afirmação de políticas sociais quanto o acirramento das premissas neoliberais. A difusão das políticas neoliberais traz consigo um processo de intensificação das desigualdades em diversos países (HARVEY, 2008; PIKETTY, 20I4). Apesar da crescente concentração de renda, o Brasil experimentou durante a primeira década dos anos 2000 um período de expansão do emprego e da atividade econômica. Entre 2004 e 2014 foram criados pouco mais de I4 milhões de empregos formais, e mesmo diante da crise econômica de 2008 o país fechou o ano com crescimento igual a 5\% e a criação de I,5 milhões de novos postos de trabalho (MATTOS; LIMA, 20I5).

Além desse crescimento, o contexto também sinaliza com uma maior inserção feminina no mercado formal de trabalho. O pós-década de 1990 indica avanços para a situação da mulher no mundo do trabalho e a igualdade de gênero na sociedade. Ao mesmo tempo, os dados indicam que as mulheres não só têm menos probabilidade de participar do mercado de trabalho do que os homens, mas também as que participam têm menos probabilidade de encontrar empregos, ou quando encontram eles estão fora da legislação trabalhista, regulamentos de segurança social e acordos coletivos (OIT, 20I8). Assim, o emprego precário e a informalidade afetam mais as mulheres, principalmente nos países em desenvolvimento, ainda que os homens também estejam aumentando sua inserção nessa lógica do trabalho. 


\section{C) HițTó T́RICA}

Atualmente metade das famílias brasileiras são chefiadas por mulheres. De modo que essa associação imediata do sexo masculino a imagem do chefe de família não possui uma correspondência com os dados empíricos como antes. Conforme é possível ver a seguir no gráfico I, em pouco mais de duas décadas o crescimento de lares chefiados por mulheres cresceu significativamente, ao passo que o número relativo de domicílios chefiados por homens diminuiu.

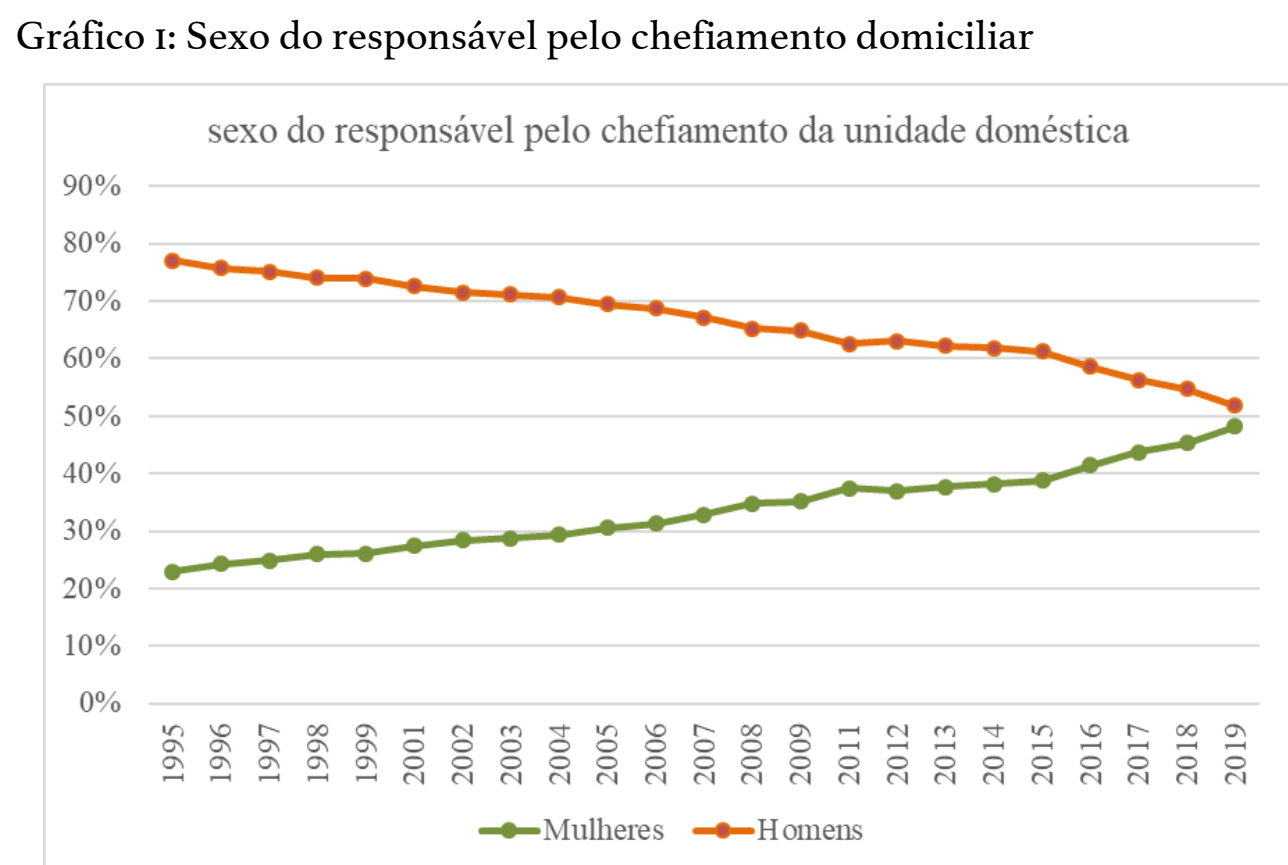

Fonte: IBGE/PNAD

Elaboração: Próprio autor

Se em 1995 os domicílios chefiados por mulheres representavam 22,9\%, em 2019 esse percentual é de $48,2 \%$. Além de um crescimento relativo, ocorreu um crescimento absoluto no número de famílias com chefiamento feminino. Nesse período de pouco mais de duas décadas, o registro de famílias chefiadas por mulheres saltou de 9,5 milhões em 1995 para 34,9 milhões em 20I9, ou seja, 25,3 milhões de novas famílias foram registradas com a mulher como principal referência em relação a renda. Ao passo que o chefiamento masculino cresceu com menor intensidade, passando de 32,I milhões em I995 para 37,5 milhões em 2019.

Esse crescimento no número de domicílios chefiados por mulheres ocorreu em todas as regiões do Brasil. A região Sudeste é onde há o maior número de domicílios chefiados por mulheres, seguido da região Nordeste, em terceiro lugar vem a região Sul, seguida da região Centro-Oeste e por fim a região Norte. Entretanto, vale notar que a região Norte é onde houve o maior crescimento relativo do período (CAVENAGHI; ALVES, 20I8). 


\section{C) HitșTórica}

A correspondência das mulheres ao lugar de chefe de família não decorre somente do fato destas serem mães solteiras. Embora a maior parte dos arranjos domiciliares de famílias monoparentais possuam chefiamento feminino, aproximadamente $87 \%$; já nos arranjos unipessoais elas representam cerca de metade (50\%); e são minoria nas famílias nucleares (23\%). Contudo, foi no núcleo duplo onde ocorreu o maior avanço no chefiamento feminino (IPEA, 20I7; CAVENAGHI; ALVES, 20I8).

Essa mudança no chefiamento das famílias possui relação direta com a inserção feminina no mercado de trabalho formal e do aumento da escolaridade das mulheres que as levou a assumir posições sociais de melhor remuneração. Com uma melhora nas condições de renda das mulheres, quando comparadas as gerações anteriores, elas passam a dispor de maior autonomia no âmbito familiar compostas por homem e mulher, ressignificando o papel do patriarca. Em pesquisa realizada por Kathya Araújo e Danilo Martuccelli (20I2) sobre os desafios vividos por chilenos/chilenas após décadas de políticas neoliberais, é possível ouvir mulheres que veem na inserção laboral um meio de construir independência, autonomia e vínculos sociais para além daqueles mantidos no lar.

Ao obter trabalho e renda, as mulheres dão importantes passos em direção a igualdade de gênero. É importante destacar que o trabalho formal assalariado se constitui como uma conquista para as mulheres. Uma conquista baseada em lutas. A inserção das mulheres em profissões majoritariamente realizadas, até então, por homens é efetivada com enfrentamentos, de desafios impostos, inclusive, por homens. Entre esses desafios estão vivências de discriminação na qual são desvalorizadas ou invejadas pelos ganhos que obtém, penalizadas por engravidar, assediadas sexualmente e/ou enfrentam desconfiança em relação a suas capacidades de realização das atividades. Para enfrentar esses desafios, as mulheres empregam estratégias como negar a discriminação, trabalhar com mais empenho, ocultar aspectos que remetam a feminilidade e/ou performar algumas características tradicionalmente atribuídas aos homens (MARQUES, 20II).

O chefiamento familiar feminino, diante das atuais desigualdades de gênero, pode significar sobrecarga de trabalho para as mulheres. Há, nesse aspecto, diferenças entre mulheres dos setores populares e de classes médias. Enquanto as mulheres chefes de família 


\section{C) GitistóñICA}

das classes médias contam com mais suportes para lidar com o chefiamento da família, ao dispor de maior quantidade e qualidade de eletrodomésticos, assim como babás e diaristas, as mulheres dos setores populares tendem a realizar mais trabalho para atender as diferentes jornadas de trabalho dentro e fora de casa (OLIVEIRA, 20I4).

Essa sobrecarga de trabalho também é reforçada pelo fato de os homens trabalharem menos nas atividades domésticas que as mulheres. Segundo dados da Pesquisa Nacional por Amostra de Domicílios Contínua - PNAD Contínua (IBGE, 2020) a taxa de realização de afazeres domésticos no próprio domicílio para a população de I4 anos ou mais é de 86\% para o ano de 20I9, sendo que assinalaram fazer atividades $92 \%$ das mulheres e $79 \%$ dos homens. Ainda que já seja possível verificar desigualdades em quem faz e quem não faz atividades no domicílio, essa desigualdade fica ainda mais evidente quando calculadas as horas médias dispendidas para a realização das atividades. Enquanto os homens de I4 anos ou mais de idade dedicam em média II horas na semana aos afazeres domésticos e/ou às tarefas de cuidado de pessoas, as mulheres dedicam 2I horas para a realização dessas mesmas atividades. Os tipos de atividades também apontam persistentes desigualdades, elas são as que mais realizam atividades como preparar alimentos, cuidar da limpeza, arrumar o domicílio, cuidar dos animais, fazer compras e pagar contas; apenas em pequenos reparos e consertos na casa e no carro, os homens são mais presentes.

A perda do status de provedor envolve questões geracionais à medida que as próprias trajetórias de transição para a vida adulta de jovens homens estão mudando. Anteriormente, a condição de estudante estava relacionada a infância e a dependência dos pais, enquanto a imagem do homem adulto vinculava-se a do trabalhador chefe de família com esposa e filhos que encerrou sua trajetória escolar. Atualmente, com novas possibilidades de prolongamento da escolarização, os desafios para inserção no mundo do trabalho e mudanças na vida conjugal, se misturam e se confundem levando a uma ampla gama de outras trajetórias de vida (VIEIRA, 2008).

Além das mudanças geracionais na transição para a vida adulta, dos avanços femininos no âmbito do trabalho, possibilitando a elas obter maior renda e participação na economia domésticas, o declínio do provedor chefe de família também tem ocorrido por conta de mudanças na própria composição familiar e, consequentemente, na figura paterna.

O processo de migração do campo para as cidades foi um dos primeiros passos importantes para as transformações no âmbito conjugal e familiar, bem como da mudança no chefiamento familiar. Enquanto a população urbana cresceu de I8,8 milhões de pessoas em I950 para I60,9 milhões em 20ı0, já a população rural diminuiu, passando de 33,2 milhões 


\section{C) HițTó T́RICA}

em 1950 para 29,9 milhões, em 2010 (ALVES; CAVENAGHI, 2012). Segundo May Del Priore (2013, p. I79) A transição do meio rural para os meios urbanos resultou na "perda de prestígio do patriarca" e dos papéis por ele exercidos na comunidade. Essa transição significou mudanças na constituição das identidades seja de pai, seja de filho, seja de homem. A autora ainda argumenta que

o pai foi, durante séculos, um mecanismo fundamental de estruturação de famílias, principalmente de seu poder. Ele era um eficiente mecanismo de articulação da família com o Estado e a igreja. Ele representava uma genealogia, um nome e o sangue, e, em muitos casos, a influência política de famílias, reunidas em torno de um patriarca mais forte ainda. E, mesmo nas famílias pequenas e reduzidas, ele era a voz do comando (DEL PRIORE, 2013, p. 158-159)

Demograficamente é importante assinalar que quando o número de famílias está crescendo mais rápido do que a população brasileira, isto significa que o tamanho médio de cada família está ficando menor (CAVENAGHI; ALVES, 20I8). A queda na taxa de fecundidade tem promovido um deslocamento das estruturas sociais. Diferenciais importantes foram apontados, revelando queda mais acentuada naqueles grupos onde a fecundidade era mais elevada na década de 1990, ou seja, entre as mulheres mais pobres, menos escolarizadas, negras, domiciliadas nas áreas rurais, e nas regiões Norte e Nordeste; além disso, essa queda também aparece entre as mulheres jovens (BERQUÓ; CAVENAGHI, 2006; ALVES; CAVENAGHI, 2012). A redução das taxas de fecundidade permite que as mulheres gastem menos tempo nas tarefas de trabalho do lar e mais tempo em atividades relacionadas a educação e trabalho. E assim, essa queda na fecundidade nas gerações pósdécada de 1990 indicam uma mudança em relação as concepções tradicionais de família.

Nunca houve unanimidade na formação da família brasileira, mas, evidentemente, o grau de variação não poderia ser tão elevado no período em que a economia brasileira era baseada na atividade do campo. No processo de modernização da estrutura produtiva com a industrialização, a formação das grandes cidades e a vida urbana, a diversificação e a pluralidade dos arranjos familiares encontram terreno. Nesse sentido, verificou-se que entre as décadas de 1990 e 2010 no Brasil, as pessoas morando sozinhas aumentam seu peso relativo de $9, \mathrm{I} \%$ para quase $\mathbf{I 5 \%}$. Na mesma linha, os casais sem filhos passam de $14 \%$ para quase 20\% (CAVENAGHI; ALVES, 20I8).

Todavia, mesmo em famílias monoparentais chefiadas por mulheres, a figura paterna ainda carrega elementos de uma concepção tradicional de homem. Segundo Juliana Perucchi e Aline Beirão (2007), mães que exercem o chefiamento do lar ainda compartilham de concepções cuja figura paterna é associada a autoridade e ao "pulso firme". Nessas 


\section{C) GitistóñICA}

famílias, o pai deixa de ser visto como o provedor e assume um lugar de educador na relação com o(s)/a(s) filho(s)/filha(s).

Essa mudança da figura do pai provedor para o pai educador desponta como uma tendência. As possibilidades de construção de famílias sem a figura paterna, associado as conquistas de direitos das crianças e das mães, implicam maior responsabilização dos pais.

Além disso, é importante destacar que atualmente algumas políticas têm sido implementadas para que os pais cumpram com as pensões alimentícias dos filho(s)/filha(s) que moram com as mães. Tais políticas devem ser interpretadas como políticas que movimentam estruturas sociais e relações de gênero, haja vista que (I) aproximam os pais do(s)/da(s) filho(s)/filha(s), fortalecendo os laços de paternidade; (II) fortalece relações de confiança entre homens e mulheres, à medida que os pais cumprem com parte das necessidades de suporte dos dependentes; (III) Faz com que os homens desenvolvam afetos e ações de cuidado, algo negligenciado na aquisição do set de práticas sociais consideradas adequadas aos "homens de verdade"; e (IV) Possibilita a mulher dispor de maior renda, atender as próprias necessidades e exercer a cidadania.

Essa ressignificação da figura do pai enquanto provedor também está relacionada à precarização das condições de trabalho que atingiu homens e mulheres, especialmente de gerações atuais. Cada vez mais se presencia o desmonte do modelo de remuneração das sociedades industriais na qual o homem recebia um salário equivalente as necessidades de sustento da família. Esse modelo estava amparado na divisão sexual do trabalho que remetia, em linhas gerais, a associação do homem ao espaço público e da mulher ao espaço privado. Ainda que, atualmente, o acesso ao emprego formal seja estruturado em uma pirâmide na qual o homem branco, seguido do homem negro estejam colocados acima da mulher branca e da mulher negra (IPEA, 20I7), a dissolução desse modelo das sociedades industriais contribuiu para a dissolução desse status de provedor.

Em síntese, o cenário atual tem despontado com um movimento de ascensão da presença da mulher no mercado de trabalho, uma tendência a perda cada vez mais evidente do status de provedor aos homens, acompanhada de uma desconstrução da acepção tradicional de família, e o aumento na responsabilização dos pais nos direitos dos/das filhos/filhas.

Medo, ressentimento e a tentativa de voltar àquilo que se perdeu 


\section{C) Hitsistórica}

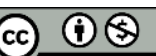

A diminuição da desigualdade da renda média entre homens e mulheres, entre homens brancos e homens negros; a crescente inserção das mulheres no mercado de trabalho, permitindo novas configurações nos lares; têm levado os homens a sentir que sua hegemonia está cada vez mais ruindo. Há, também, uma dimensão geracional nessas mudanças, os homens que vivem essa nova realidade não são os mesmo de décadas anteriores à 1990, embora continuem sendo homens educados por essa cultura familiar. Portanto, se o gênero se constitui enquanto uma corporificação do social, o período neoliberal, com todos os direitos adquiridos e perdidos, tem incidido com a produção social de formas de ser homem.

Com privilégios de gênero assegurando diversos direitos e uma ausência de questionamento de si, os homens percebem-se como detentores "naturais" daquilo que obtém com seus privilégios. O senso de direito [entitlement] é marca historicamente constitutiva da construção social da masculinidade (KIMMEL, 20I7), especialmente do chefe de família, haja vista o poder do patriarca nas configurações rurais ou do chefe de família urbano, os privilégios passaram a ser incorporados pelos homens em um senso de direito. Pelo senso de direito os homens esperam que as ações digam respeito a eles, de modo a possuírem direito à participação "naturalmente" assegurado nos grupos e instituições.

A partir dos direitos historicamente adquiridos, esse senso de direito possibilita a formação de uma cultura do direito [culture of entitlement] (KIMMEL, 20I8a). Pela cultura do direito, enquadrar-se nas normativas de comportamento masculino surge como uma recompensa. Ao trabalhar e/ou se sacrificar para ser aquilo que é ditado na arena da homossociabilidade masculina, os homens supõem implicitamente que possuem o direito de exercer poder sobre as mulheres, bem como os homens ou garotos que não se enquadram nessas normativas.

A medida que se encontram diante de um cenário em que precisam disputar lugares no mercado de trabalho com aqueles/aquelas que foram desfavorecidos socialmente pelos critérios de gênero, sexualidade e/ou raça, ou quando percebem que a mulher pode colocar um fim a relação conjugal quando se sentir desvalorizada na relação, os homens passam a sentir o senso de direito lesado, e assim, medo.

Todavia, o medo é um sentimento que os homens aprendem desde meninos a suprimir, especialmente na esfera pública, de modo que eles passam a expressar outro sentimento melhor socialmente aceito: o ressentimento.

Ressentir-se envolve atribuir ao outro a responsabilidade pelo próprio sofrimento, colocando-se em posição de vítima, mas, mantendo uma expressão de raiva. O sofrimento se 


\section{C) Hitistór RICA}

mantém por meio de uma repetição da dor, sem a capacidade de perdão ou reconhecimento da própria responsabilidade ante a ruminação, sendo assim, o indivíduo não tem capacidade de desincumbir-se moralmente da dor que sentiu (KEHL, 2020). Ainda que não possa ser confundido com a raiva, o ressentimento também é constituído por expressões de raiva e ódio.

Raiva e ódio são dois sentimentos que os homens conhecem muito bem. Se durante o processo pelo qual os garotos tornam-se homens eles precisam suprimir seus sentimentos para serem reconhecidos como "homens de verdade", no intuito de não serem associados a representações tidas como femininas, a raiva e o ódio são sentimentos socialmente "legítimos" para a construção social da masculinidade.

Para Maria Rita Kehl (2020, p. 9) “A atualidade do ressentimento, enquanto tema, é clínica e também política”. O contexto neoliberal, pós-crise de 2008, emerge com figuras políticas que combinam posturas liberais na economia e conservadoras na moralidade. $\mathrm{O}$ ressentimento tem, em geral, gênero, raça e sexualidade, isto é, seus representantes geralmente são homens, brancos e heterossexuais. A precariedade do trabalho, as poucas políticas de assistência social e bem-estar fez uma camada da população buscar culpados. Já para Wendy Brown

Além de empobrecidos e frustrados, os cristãos brancos, rurais ou suburbanos, eram deixados de lado e para trás, alienados e humilhados. E havia o racismo duradouro, crescente conforme novos imigrantes transformaram bairros suburbanos e conforme políticas de "equidade e inclusão" pareceram, ao homem branco não escolarizado, favorecer a todos, menos a ele. Assim, as agendas políticas liberais, as agendas econômicas neoliberais e as agendas culturais cosmopolitas geraram uma crescente experiência de abandono, traição e finalmente raiva por toda a parte dos novos despossuídos, das populações da classe trabalhadora e da classe média branca do Primeiro Mundo e do Segundo." (BROWN, 20I9, p. II)

Conforme apontou Arlie Hochschild (2016) em estudo etnográfico junto a eleitores pobres de Donald Trump, essa percepção de que o Estado só favorece as "minorias" foi compartilhado até por brancos e de pouca escolaridade moradores de regiões pobres dos Estados Unidos. Na ausência de uma crença na resolução dos problemas sociais pelas vias da disputa do jogo democrático, esses sujeitos passam a compartilhar da crença de que são esquecidos pela ação estatal. E ainda mais, compartilham da existência de um suposto "racismo reverso" promovido tanto pelo Estado, quanto por indivíduos membros de alguns movimentos sociais. 


\section{C) Gitistór RICA}

Essa crença em um "racismo reverso" é sintoma de um ressentimento de ordem política. O ressentimento não é só destrutivo, mas, também produtivo. Conforme apontou Nietzsche (2009, p. 26) em A genealogia da moral,

A rebelião escrava na moral começa quando o próprio ressentimento se torna o criador e gera valores: o ressentimento dos seres aos quais é negada a verdadeira reação, a dos atos, e que apenas por uma vingança imaginária obtém reparação.

O ressentimento surge como uma resposta dos homens ao declínio da figura de provedor chefe de família que veem diante dos seus olhos uma crescente libertação das mulheres as normativas tradicionais de sexualidade e conjugalidade. A dimensão produtiva do ressentimento fomenta um niilismo que desvaloriza tanto os valores morais hegemônicos quanto as regras democráticas estabelecidas, reforçando um conjunto de premissas moralistas.

O poder político do ressentimento masculino não influenciou somente as eleições americanas, mas, também, o processo de impeachment de Dilma Housseff e a ascensão de Jair Bolsonaro nas eleições de 20I8. O ódio tornou-se uma arma política no Brasil, e com ele ocorre o fomento da intolerância e do autoritarismo (GALLEGO, 20I8). Essa face intolerante do ressentimento também está ameaçando as estruturas democráticas do Estado. Não somente esses homens do século XXI, mas também os pensadores fundantes do neoliberalismo não se colocam defensa da democracia.

Pensadores neoliberais viam o político com desconfiança, e [...] abertamente hostis tanto à sua variante soberana quanto à democrática. $\mathrm{O}$ neoliberalismo, deste modo, visa limitar e conter o político, apartando-o da soberania, eliminando sua forma democrática e definhando suas energias democráticas. De suas aspirações e afirmação "pós-ideológicas" da tecnocracia até sua economicização e privatização das atividades governamentais" (BROWN, 2019, p. 70).

As percepções dos neoliberais implicam em uma cultura antipolítica. Assim, o autoritarismo e os discursos de ódio impactam diretamente a vida das mulheres. Além de incitar a discriminação sexual e de gênero, essa face do ressentimento isenta do Estado a necessidade de formular políticas públicas de suporte aos indivíduos, especialmente mulheres negras e/ou de classe trabalhadora.

Subjacente a essa desvalorização do Estado, há, também, uma responsabilização do sucesso e do fracasso do sujeito pela lógica neoliberal. Ao pensar os sentidos discursivos assumidos pela responsabilidade, Judith Butler (2019, p. 20) entende que

[...] de acordo com os que valorizam a destruição dos serviços sociais, somos responsáveis apenas por nós mesmos e certamente não pelos outros, e se a 
responsabilidade é em primeiro lugar e acima de tudo uma responsabilidade de se tornar economicamente autossuficiente em condições que minam todas as perspectivas de autossuficiência, então estamos confrontando com uma contradição que pode facilmente levar uma pessoa à loucura: somos moralmente pressionados a nos tornar precisamente o tipo de indivíduo que está estruturalmente impedido de concretizar essa norma.

Essa mesma racionalidade culmina na destruição da efetivação da autossuficiência econômica. Quando alguém se prova incapaz de efetivar a norma da autossuficiência ela passa a ser potencialmente dispensável (BUTLER, 20I9). Sendo assim, o declínio da capacidade de ser economicamente autossuficiente e manter a hegemonia de provedor chefe de família leva os homens a essas demonstrações de ódio e raiva. Todavia, ocorre um movimento de universalização da autossuficiência masculina, ocorre a defesa da responsabilidade familiar e de parentesco, mantém-se a desincumbência do Estado e do capital nas questões públicas, ao mesmo tempo que justifica desigualdades e situações de precariedade (COOPER, 20I7).

A aparição na cena pública de grupos de extrema direita ${ }^{8}$ cuja composição é majoritariamente masculina não ocorre por acaso. Tais grupos tendem a reproduzir valores rígidos de masculinidade, assumindo premissas como: recorrer ao uso da força e da violência para a resolução de conflitos e ocupar espaços, negar qualquer prática que possa ser associada ao "feminino" e expressar homofobia e rejeição a pessoas LGBT. Ao realizar um estudo com jovens ex-membros de grupos de extrema-direita em países como Alemanha, Suécia, Estados Unidos e Inglaterra, Michael Kimmel (2018b) percebeu que os rapazes que entravam nesses grupos estavam em busca de restaurar a masculinidade perdida em situações de violência na escola e conflitos com os pais. Ao serem temidos nas ruas e respeitados nos grupos, eles sentem-se, a partir de referenciais tradicionais de masculinidade, "homens de verdade".

Esse protagonismo masculino em movimentos de direita aparece com maior visibilidade, sobretudo, em grupos defensores dos "direitos dos homens" (JORDAN, 20I6) ou grupos defensores dos "direitos dos pais" (JORDAN, 20I4). A origem dos movimentos de direitos dos homens está em meados da década de I970. Durante essa década grupos masculinos realizavam uma crítica aos papéis de gênero, porém, com o tempo, houve uma ramificação em três grupos: o primeiro contempla a luta dos homens gays, bissexuais,

\footnotetext{
${ }^{8} \mathrm{Na}$ análise de Brown, olhando para os Estados Unidos, a autora aponta que defesa da privatização e, mais que isso, uma "desestatização" "preparou o terreno para alianças improváveis entre libertários econômicos, plutocratas, anarquistas armados de direita, vigilantes da Ku Klux Klan, opositores do aborto e praticantes do ensino domiciliar" (BROWN, 20I9, p. 72).
} 


\section{C) CitceátórICA}

transexuais, o segundo a luta em defesa da igualdade de gênero e um terceiro de homens que alegam serem lesados por um Estado que defende apenas as mulheres. Grupos como o MGTOWN - Men Going Their Own Way -, AVfM - A Voice for Men - ou o Fathers4justice.

E essa onda masculina antagônica ao feminismo também têm chegado ao Brasil. Já é possível encontrar núcleos parecidos no Brasil. Embora esses núcleos não tenham uma organização formal da AVfM, esses homens têm se organizado em grupos de discussão na internet, seja pelas redes sociais, seja por fóruns ${ }^{9}$. Mas também, considerando o crescimento das igrejas evangélicas no país, há também grupos formados membros religiosos que promovem encontros para fortalecer a "masculinidade, espiritualidade e o empreendedorismo entre homens"

É no ínterim dessa responsabilização paterna que aparecem os homens apoiadores dos grupos de defesa dos direitos dos pais, geralmente irritados com as (ex) esposas, os/as advogados/advogadas das ex-esposas e com as leis do Estado em relação ao matrimônio e a paternidade (JORDAN, 20I4, 20I6; KIMMEL, 20I7). De modo que esses grupos colocam os homens em uma posição de vítima, justificando a afirmação de políticas neoconservadoras (COOPER, 20I7).

Logo, o aparecimento de diversos homens brancos na cena pública, defendendo uma "volta ao passado" como forma de reestabelecer a ordem e os valores da família tradicional, expressam elementos de sua condição de gênero. Gritar a volta ao passado é gritar em busca de um conjunto de experiências de masculinidade que já não se sustentam mais (KIMMEL, 20I7).

\section{Considerações finais}

Mediante o exposto, identificamos ou é possível afirmar que há uma tendência de mudança no chefiamento das famílias, com maior representação feminina. Isso deriva da inserção feminina no mercado formal de trabalho, mas não somente, as configurações

\footnotetext{
9 Para saber mais confira em: GERMANO, Felipe; KORTE, Júlia. Em defesa do macho oprimido: um movimento internacional promete lutar pelos direitos dos homens contra a opressão do feminismo. Época, São Paulo, I3 de ago. 20I4, Vida, Disponível em: https:/epoca.globo.com/vida/noticia/20I4/o8/em-defesa-dobmacho-oprimidob.html. Acesso em out. de 2020.

Io Para saber mais confira em: DIAS, Tiago. Em plena onda feminista, Machonaria quer resgatar masculinidade patriarcal. Uol, São Paulo, 8 de nov. 2019, Sociedade. Disponível em: https:/tab.uol.com.br/noticias/redacao/20I9/II/o8/eventos-como-machonaria-querem-resgatar-amasculinidade-patriarcal.htm. Acesso em out. de 2020; MOTTA, Zilá. Polêmico, evento em Brasília quer resgatar "masculinidade patriarcal”. Metrópoles, Distrito Federal, 4 de set. 20I9, Vida \& stilo. Disponível: https://www.metropoles.com/vida-e-estilo/polemico-evento-em-brasilia-quer-resgatar-masculinidadepatriarcal . Acesso em out. de 2020.
} 


\section{C) GitistóñICA}

familiares estão progressivamente mudando, alterando a posição das mulheres nos domicílios. Se, de um lado, as mudanças atuais têm suscitado discursos de empoderamento feminino, de outro lado, tem suscitado uma suposta "crise da masculinidade".

Até a pandemia do novo coronavírus (SARS-CoV-2), há tendência era que o número de mulheres chefes de família ultrapassasse o de homens em alguns anos. Contudo, algumas fontes têm apontado uma retração no emprego feminino durante a pandemia e a ameaça de contensão de alguns avanços, especialmente em países cujas políticas para diminuir os impactos sobre as mulheres são menos efetivas (ONU, 2020).

A efetivação de políticas públicas também é um elemento importante para os avanços em índices de igualdade de gênero (OIT, 20I8). No entanto, o avanço do neoconservadorismo e das políticas neoliberais significam estagnação ou até retrocessos nas conquistas femininas/feministas recentes. A ascensão de homens defensores do "enxugamento da máquina pública" e que não contemplam pautas que beneficiam a melhora nas condições de vida das mulheres em suas agendas traz consigo desafios para a luta em defesa da igualdade de gênero.

O ressentimento não está situado como uma consequência monocausal das conquistas femininas/feministas. Mas, trata-se de um elemento emergente para compreender aspectos da performatividade masculina, especialmente brancos e heterossexuais, frente a esse cenário de conquistas femininas/feministas e uma suposta "crise da masculinidade".

Diante desse quadro de ressentimento masculino, o engajamento dos homens em ações coletivas de luta contra o sexismo torna-se uma saída importante. Por mais que forças (neo)conservadoras tentem conter as ondas feministas, elas estão ocupando cada vez mais espaços. É importante que os homens entendam que ao perceber os privilégios, eles tornamse capazes de compreender mais sobre si mesmo e sobre os outros. E enfim, estabelecer as conexões que eles, muitas vezes, evitaram durante uma vida, por medo de não serem considerados "homens de verdade".

O fim dos privilégios não significa que os homens venham a perder os direitos que usufruem, apenas que esses direitos também devem ser concedidos as mulheres. Acrescentar que a igualdade de gênero não é uma soma de forças igual a zero, isto é, para um ganhar o outro tem que perder (KAUFMAN; KIMMEL, 20II). Em países com maior igualdade de gênero, nos quais as mulheres passam menos horas trabalhando, dentro e fora do domicílio, são países com melhores índices de educação e menores índices de violência. Bom para todos e todas. 


\section{C) Hitsistórica}

\section{Referências}

ALVES, José Eustáquio; CORREA, Sônia. Igualdade e desigualdade de gênero no Brasil: um panorama preliminar, I5 anos depois do Cairo. In: ABEP. Brasil, I5 anos após a Conferência do Cairo. Campinas: ABEP; UNFPA., 2009. Disponível em: http://www.abep.org.br/publicacoes/index.php/livros/article/viewFile/IIz/III Acesso em out. de 2020.

; CAVENAGHI, Suzana. Transições urbanas e da fecundidade e mudanças dos arranjos familiares no Brasil. Cadernos de Estudos Sociais, v.27, n.2, jul/ago de 2012. Disponível em:https://periodicos.fundaj.gov.br/CAD/article/view/19/22 acesso em out. de 2020.

ARAÚJO, Kathya; MARTUCCELLI, Danilo. Desafios comunes: retratos de la sociedad chilena y sus individuos. Neoliberalismo, democratización y lazo social. Santiago: LOM, 2012.

BAUBÉROT, Arnaud. Não se nasce viril, torna-se viril. In: CORBIN, Alain; COURTINE, Jean-Jacques; VIGARELLO, Georges. A história da virilidade: a virilidade em crise? Séculos XX-XXI. Petrópolis, RJ: Vozes, 2013.

BERQUÓ, Elza; CAVENAGHI, Suzana. Breve nota sobre a redução no número médio de filhos por mulher no Brasil. Novos Estudos CEBRAP, v.74, mar. 2006. Disponível em: https://www.scielo.br/scielo.php?script=sci_arttext\&pid=SoIOI-33002006000I0000I acesso em out. de 2020

BOURDIEU, Pierre. A dominação masculina. $6^{\mathrm{a}}$ Ed. Rio de Janeiro: BestBolso, 2018.

BRANDÃO, Zaia. Jogo de escalas na sociologia da Educação. Educação e Sociedade, Campinas, vol. 29, n. I03, p. 607-620, maio/ago. 2008. Disponível em: https://www.scielo.br/pdf/es/v29nI03/15.pdf Acesso em out. de 2020.

BRANNON, Robert; DAVID, Deborah. The forty-nine per cent majority. MA: Addison Wesley, I976.

BROWN, Wendy. Nas ruínas do neoliberalismo: ascenção da política antidemocrática no ocidente. São Paulo: Editora Politéia, 2019.

BUTLER, Judith. Problemas de gênero: feminismo e subversão da identidade. Rio de Janeira: Civilização Brasileira, 2003.

Corpos em aliança e a política das ruas: notas para uma teoria performativa de assembleia. Rio de Janeiro: Civilização Brasileira, 2019.

CAVENAGHI, Suzana; ALVES, José Eustáquio. Mulheres chefes de família no Brasil: avanços e desafios. Rio de Janeiro: ENS-CPES, 2018.

CHABAUD-RYCHTER, Danielle et all (orgs). O gênero nas Ciências Sociais: releituras críticas de Max Weber a Bruno Latour. Brasília: Editora Unesp e Editora Universidade de Brasília, 2014 .

CONNELL, Raewyn. Gênero em termos reais. São Paulo: nVersos, 2016.

; MESSERCHMIDT, James. Masculinidade hegemônica: repensando o conceito. Estudos Feministas, Florianópolis, v.2I, n.I, jan./abr. 20I3. Disponível em: 


\section{C) GitistóróRICA}

https://www.scielo.br/scielo.php?script=sci_arttext\&pid=SoIO4026X2013000IO00I4\&lng=pt\&tlng=pt Acesso em out. de 2020.

; PEARCE, Rebecca. Gênero: uma perspectiva global. São Paulo: nVersos, 2015.

COOPER, Melinda. Family values. New York: Zone Books, 2017.

CORBIN, Alain; COURTINE, Jean-Jacques; VIGARELLO, Georges. A história da virilidade: a virilidade em crise? Séculos XX-XXI. Petrópolis, RJ: Vozes, 2013.

COSTON, Bethany; KIMMEL, Michael. Seeing Privilege Where It Isn't: Marginalized Masculinities and the Intersectionality of Privilege. Journal of Social Issues, v. 68, n. I, p. 97-III, 2012.

D’AVILA, Sande Maria Gurgel. Cotidiano e relações de gênero em famílias de mulheres provedoras. 2008. 2I8f. - Tese (Doutorado) - Universidade Federal do Ceará, Programa de Pós-graduação em Sociologia, Fortaleza (CE), 2008. Disponível em: http://www.repositorio.ufc.br/handle/riufc/II782 Acesso em out. de 2020.

DEL PRIORE, Mary; AMANTINO, Marcia. (orgs.) História dos homens no Brasil. São Paulo: Editora Unesp, 2013.

. Pais de ontem: transformações da paternidade no século XIX. In: DEL PRIORE, Mary; AMANTINO, Marcia. (orgs.) História dos homens no Brasil. São Paulo: Editora Unesp, 2013.

DIAS, Tiago. Em plena onda feminista, Machonaria quer resgatar masculinidade patriarcal. Uol, São Paulo, 8 de nov. 2019, Sociedade. Disponível em: https://tab.uol.com.br/noticias/redacao/20I9/II/o8/eventos-como-machonaria-queremresgatar-a-masculinidade-patriarcal.htm. Acesso em out. de 2020.

GALLEGO, Esther Solano. (org.) O ódio como política: a reinvenção da direita no Brasil. São Paulo: Boitempo, 2018.

GERMANO, Felipe; KORTE, Júlia. Em defesa do macho oprimido: um movimento internacional promete lutar pelos direitos dos homens contra a opressão do feminismo. Época, São Paulo, I3 de ago. 20I4, Vida, Disponível em: https://epoca.globo.com/vida/noticia/20I4/o8/em-defesa-do-bmacho-oprimidob.html.

Acesso em out. de 2020.

GIL, Antônio Carlos. Métodos e técnicas de pesquisa social. 6. ed. São Paulo: Atlas, 2008.

HARVEY, David. Neoliberalismo: história e implicações. São Paulo: Loyola, 2008.

HILL COLLINS, Patricia. Toward a new vision: race, class and gender as categories of analysis and connection. In: KIMMEL, Michael; FERBER, Abby (orgs). Privilege. $2^{\text {a }}$ Ed. Philadelphia: Westview Press, 2010.

HIRATA, Hirata Sumiko. Novas Configurações da Divisão Sexual do Trabalho. Revista Tecnologia e Sociedade, Curitiba, v.6, n.II, p. I-7, jul-dez, 20I0. Disponível em: https://periodicos.utfpr.edu.br/rts/article/view/2557 Acesso em out. de 2020.

HOCHSCHILD, Arlie. Strangers in their own land. New York: The New Press, 2016.

HOOKS, bell. The will to change: men masculinities and love. New York: Washington Square Press, 2004. 


\section{C) GitistóróRICA}

IBGE. Pesquisa Nacional por Amostra de Domicílios Contínua. Rio de Janeiro: IBGE, 2020. Disponível em: https://www.ibge.gov.br/estatisticas/sociais/populacao//7270-pnadcontinua.html?edicao=264I3\&t=0-que-e Acesso em: jun. de 2020.

. Indicadores sociais 20I8: tabulações especiais sobre as condições de vida da população brasileira : notas técnicas. Rio de Janeiro: IBGE, 2020.

IPEA. 20I7. Retrato das desigualdades de gênero $e$ raça. Disponível em: https://www.ipea.gov.br/retrato/index.html. Acesso em: ago. de 2020.

JOHSNSON, Allan. Privilege, power, difference, and us. In: KIMMEL, Michael; FERBER, Abby (orgs). Privilege. $2^{\mathrm{a}}$ Ed. Philadelphia: Westview Press, 2010.

JORDAN, Ana. 'Every Father is a Superhero to His Children':The Gendered Politics of the (Real) Fathers 4 Justice Campaign. Political Studies, v.62, p.83-98, 2014.

. Conceptualizing Backlash: (UK) Men's Rights Groups, Anti-Feminism, and Postfeminism. Canadian Journal of Women and the Law, v.28, n.I, p.I8-44, 2016.

KAUFMAN, Michael; KIMMEL, Michael. The guys's guide to feminism. California: Seal Press, 2011.

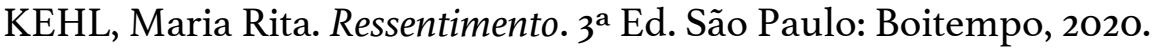

KHAN, Shamus Rahman. Privilege: the making of an adolescent elite at St. Paul's School. New Jersey: Princeton University Press, 20II.

KIMMEL, Michael. Manhood in America: a cultural history. New York: Bold Type Books, 1998. . Angry White Men. $2^{\text {a }}$ Ed. New York: Bold Type Books, 2017.

. Guyland: the perilous world where boys became men. New York: HarperCollins, 20I8a.

. Healing from hate: how young men get into-and out of-violent extremism. Califórnia: University of California Press, 2018b.

; FERBER, Abby (orgs). Privilege. $2^{\text {a }}$ Ed. Philadelphia: Westview Press, 2010.

MACEDO, Márcia dos Santos. Mulheres chefes de família e a perspectiva de gênero: trajetória de um tema e a crítica sobre a feminização da pobreza. Caderno CRH, Salvador, v. 2I, n. 53, p. 389-404, Maio/Ago. 2008. Disponível em https://www.scielo.br/scielo.php?pid=SoIO3$49792008000200013 \&$ script=sci_abstract\&tlng=pt Acesso em out. de 2020.

MARQUES, António Manuel. Masculinidades e profissões: discursos e resistências. Coimbra: Fundação Calouste Gulbenkian, 20II.

MATTOS, Fernando Augusto Mansor de; LIMA, Sergiany da Silva. Apontamentos para o debate sobre o pleno emprego no Brasil. Economia \& Sociedade. vol.24, n.2, 2015. Disponível em:https://www.scielo.br/scielo.php?pid=SoI0406182015000200293\&script=sci_abstract\&tln $\mathrm{g}=\mathrm{pt}$ Acesso em out. de 2020

MCINTOSH, Peggy. White privilege and male privilege. In: KIMMEL, Michael; FERBER, Abby (orgs). Privilege. $2^{\text {a }}$ Ed. Philadelphia: Westview Press, 20 Io.

MOTTA, Zilá. Polêmico, evento em Brasília quer resgatar "masculinidade patriarcal". Metrópoles, Distrito Federal, 4 de set. 2019, Vida \& stilo. Disponível: 


\section{C) GitistóróRICA}

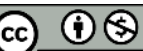

https://www.metropoles.com/vida-e-estilo/polemico-evento-em-brasilia-quer-resgatarmasculinidade-patriarcal. Acesso em out. de 2020.

NIETZSCH, Friedrich Wilhelm. A Genealogia da Moral. São Paulo: Companhia das Letras, 2009.

OIT. Perspectivas Sociales y del Empleo en el Mundo: Avance global sobre las tendencias del empleo feminino 20I8. Ginebra: OIT, 20I8. Disponível em: https://www.ilo.org/wcmsp5/groups/public/---dgreports/---dcomm/--publ/documents/publication/wcms_6r9603.pdf Acesso em out. de 2020.

OLIVEIRA, Pedro Paulo. Discursos sobre a masculinidade. Estudos Feministas, Florianópolis, v.6, n.I, p.9I-II2, I998. Disponível em: https://periodicos.ufsc.br/index.php/ref/article/view/I2036 Acesso em out. de 2020.

OLIVEIRA, Taliane Pereira. O Trabalho na Vida das Mulheres Chefes de Família. I8 ${ }^{\circ}$ Encontro Nacional da Rede Feminista Norte e Nordeste de Estudos e Pesquisas sobre a Mulher e Relações de Gênero - REDOR. 20I4. Disponível em: http://www.ufpb.br/evento/index.php/I8redor/I8redor/paper/viewFile/2280/747 Acesso em out. de 2020.

OLIVEIRA, Nadja Simone Menezes Nery de. Pobreza das mulheres chefes de família da Região Nordeste do Brasil: uma análise multidimensional. 2018. I84 f. Tese ( Doutorado em Desenvolvimento Regional e Agronegócio) - Universidade Estadual do Oeste do Paraná, Toledo, 20I8. Disponível em: http://tede.unioeste.br/handle/tede/3949 Acesso em out. de 2020.

OLIVEIRA, Caíque Diogo de. Masculinidades e neoliberalismo: possibilidades interpretativas. III Seminário (Des)Fazendo Saberes na Fronteira: Lutas e (Re)Existências. v.3, UNIPAMPA, 2020.

ONU. 2020. The Sustainable Development Goals Report 2020. Disponível em: https://unstats.un.org/sdgs/report/2020/The-Sustainable-Development-Goals-Report2020.pdf > Acesso em: out. de 2020.

PERROT, Michelle. Minha história das mulheres. São Paulo: Editora Contexto, 2007.

PERUCCHI Novos arranjos familiares: paternidade, parentalidade e relações de gênero sob o olhar de mulheres chefes de família. Psicologia clínica. Rio de Janeiro, v.I9 n..2 Dez. 2007. Disponível em: https://www.scielo.br/scielo.php?pid=s010356652007000200005\&script=sci_abstract\&tlng=p t Acesso em out. de 2020.

PETRY, A. R; MEYER, Dagmar Estermann. Transexualidade e heteronormatividade: algumas questões para a pesquisa. Textos \& Contextos, Porto Alegre), v.Io, n.I, p.I93-I98. Disponível em https://revistaseletronicas.pucrs.br/ojs/index.php/fass/article/view/7375 Acesso em out. de 2020.

PIKETTY, Thomas. O capital no século XXI. Rio de Janeiro: Intrinseca, 2014

PISCITELLI, Adriana. Re-criando a (categoria) mulher? In: ALGRANTI, Leila Mezan; PISCITELLI, Adriana; GOLDANI, Ana Maria (Orgs.). A prática feminista e o conceito de gênero. Campinas: IFCH/UNICAMP, 2002.

POLLACK, William. Meninos de verdade: conflitos e desafios na educação de filhos homens. São Paulo: Alegro, 1999. 


\section{C) Hitcastórica}

REVEL, Jacques. Jogos de escalas: a experiência da microanálise. Rio de Janeiro: FGV, I998.

ROSALDO, Michelle Zimbalist. O uso e o abuso da antropologia: reflexões sobre o feminismo e o entendimento intercultural. Revista Horizontes Antropológicos, Porto Alegre: v. I, n.I, p.II-36, I994. Disponível em: http://repositorio.ufsc.br/xmlui/handle/I23456789/I58I Acesso em: set. de 2020

SCOTT, Joan. Gênero: uma categoria útil de análise histórica. Educação E Realidade, Santa Catarina, v. 20, n. 2, jul/dez de I995. Disponível em: https://seer.ufrgs.br/index.php/educacaoerealidade/article/view/7172I Acesso em out. de 2020.

VIEIRA, Joice Melo. Transição para a vida adulta no Brasil: análise comparada entre 1970 e 2000. Revista brasileira de estudos da população, São Paulo, v. 25, n. I, p. 27-48, jan./jun. 2008. Disponível em: https:/www.scielo.br/pdf/rbepop/v25nI/v25nIa03 Acesso em out. de 2020.

VINCENT, Norah. Feito Homem: A jornada de uma mulher ao universo masculino. São Paulo: Editora Planeta do Brasil, 2006.

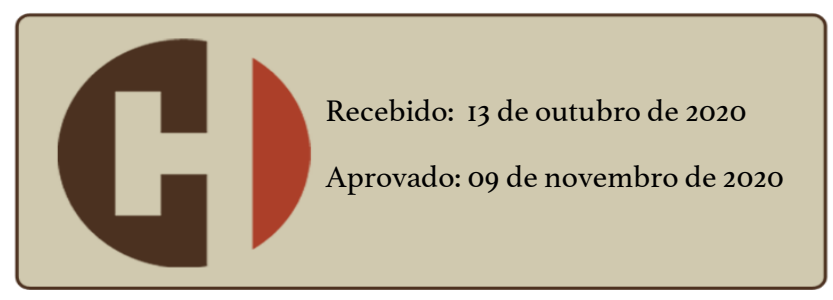

